\title{
BMJ Open Factors affecting attitudes towards caring for terminally ill patients among nursing students in Switzerland: a cross- sectional study
}

\author{
Pauline Laporte (D) , ${ }^{1}$ Typhaine Juvet, ${ }^{1}$ Jean-François Desbiens, ${ }^{2}$ Diane Tapp, ${ }^{2}$ \\ Jérôme Pasquier (D), ${ }^{3}$ Marc-Antoine Bornet (iD ${ }^{4}$
}

To cite: Laporte $P$, Juvet $T$, Desbiens J-F, et al. Factors affecting attitudes towards caring for terminally ill patients among nursing students in Switzerland: a crosssectional study. BMJ Open 2020;10:e037553. doi:10.1136/ bmjopen-2020-037553

- Prepublication history for this paper is available online. To view these files, please visit the journal online (http://dx.doi. org/10.1136/bmjopen-2020037553).

Received 20 March 2020 Revised 06 July 2020 Accepted 21 August 2020

Check for updates

(C) Author(s) (or their employer(s)) 2020. Re-use permitted under CC BY-NC. No commercial re-use. See rights and permissions. Published by BMJ.

${ }^{1}$ Haute Ecole Arc Santé, University of Applied Sciences and Arts Western Switzerland (HES-SO), Neuchâtel \& Delémont, Switzerland ${ }^{2}$ Faculty of Nursing, Laval University, Québec City, Québec, Canada

${ }^{3}$ Center for Primary Care and Public Health, University of Lausanne, Lausanne, Switzerland

${ }^{4}$ Service of Internal Medicine, Lausanne University Hospital, Lausanne, Switzerland

Correspondence to Professor Pauline Laporte; pauline.laporte@he-arc.ch

\section{ABSTRACT}

Objectives Positive attitudes towards end-of-life care are essential among nursing students to adequately support terminally ill patients and enable students to feel confident about providing end-of-life care. This study aimed to determine nursing students' attitudes towards caring for terminally ill patients, as well as the associations between these attitudes and year of study, exposure to terminally ill people, self-perceived nursing skills and subjective impact of instruction.

Design Cross-sectional study.

Setting A health sciences school in Switzerland. Participants All preparatory students, first-year nursing students and third-year nursing students were invited to participate; 178 agreed to participate.

Primary outcome measure Attitudes towards terminally ill patients were assessed using the Frommelt Attitudes Toward Care of the Dying Scale, Form B (FATCOD, Form $B)$, as the primary outcome. Secondary measures were gender, age, year of study, number of terminally ill persons encountered, self-perceived palliative care nursing skills and subjective impact of instruction.

Results Mean FATCOD, Form B score was 117.7 (SD: 9.8, median: 118.0). Better attitudes towards terminally ill patients were significantly associated with being aged 24-26 years $(\beta=6.97,95 \% \mathrm{Cl} 2.00$ to $11.95, p=0.006)$, year of study $(\beta=3.47,95 \% \mathrm{Cl} 1.69$ to $5.25, p<0.001)$, professional encounters with terminally ill patients $(\beta=3.59,95 \% \mathrm{Cl} 2.23$ to $4.95, \mathrm{p}<0.001)$ and selfperceived palliative care nursing competence $(\beta=1.23$, $95 \% \mathrm{Cl} 0.41$ to $2.04 ; \mathrm{p}=0.003$ ). In the multivariate analysis, professionally encountering terminally ill patients remained significant $(\beta=3.00 ; 95 \% \mathrm{Cl} 1.43$ to 4.57; $\mathrm{p}<0.001$ ).

Conclusions Nursing students' attitudes towards caring for terminally ill patients were positive and improved as their year of study progressed. Professional exposure to terminally ill patients was the strongest factor, followed by private encounters, self-perceived palliative care nursing skills, year of study and age.

\section{INTRODUCTION}

Caring for an end-of-life patient is a challenge that requires both advanced skills and appropriate attitudes regarding the provision of this
Strengths and limitations of this study

- This study's primary outcome measure, the Frommelt Attitudes Toward Care of the Dying Scale, Form $B$, is a widely recognised research tool.

- The response rate was high, making response bias unlikely.

- The few instances of missing data were handled by multiple imputation.

- The secondary measures were not all fully psychometrically validated.

- The sample included nursing students at one school across two sites in Switzerland.

care. The nursing skills required to care for these patients are holistic; such care includes, for example, the treatment of pain, nausea and constipation (the biological dimension); the management of anxiety, depression and agitation (the psychological dimension); caring for the patient's loved ones (the social dimension); and identifying spiritual distress (the spiritual dimension). ${ }^{1}$ In addition, endof-life patients have been shown to have a particularly strong need for open and honest communication, involvement in decisions about their care and close monitoring with regular reassessment to allow them to cope with the instability of their situation. ${ }^{2}$

Nursing students are entering a profession where contact with death often occurs on a daily basis. Many of these students consider themselves insufficiently prepared for this situation because of a lack of training. ${ }^{3}$ Notably, caring for end-of-life patients is not without consequences for these students. Some students may develop negative attitudes, such as patient avoidance, fear, selfdoubt and communication problems. ${ }^{3-5}$ Attitudes comprise ideas and beliefs that are attached to specific emotions. ${ }^{5}$ More specifically, an attitude is the way a person expresses 
beliefs (internal feelings that something is true) and values (stable and enduring beliefs regarding the importance a person attaches to something) through words and behaviours. ${ }^{6}$

In addition to the potential impact on nursing students and patients, the kinds of negative attitudes described above have a broader effect on the health system, potentially impacting students' willingness to remain in the nursing profession and worsening the shortfall in nursing specialists. ${ }^{7}$ Thus, a positive attitude towards end-of-life care, which is promoted in the nursing curriculum, is essential for students to feel confident and develop the skills necessary to offer quality, holistic nursing care to end-of-life patients. ${ }^{8}$ Unfortunately, this key theme has not yet been studied in Switzerland.

Being a woman ${ }^{9} 10$ and being young ${ }^{11}$ are associated with more negative attitudes towards caring for terminally ill patients, whereas senior staff have been found to have more positive attitudes. ${ }^{412}$ Little information has been collected regarding these attitudes among students. A study described master's students as having more positive attitudes compared with bachelor's students, ${ }^{13}$ and other evidence indicates that those who have already been exposed to death have more positive attitudes than those who have not had this exposure. ${ }^{14}{ }^{15}$ However, attitudes of preparatory students and the evolution of attitudes of bachelor's students over time have not yet been documented.

In addition to these factors, we believe it is particularly important to study modifiable factors in the curriculum, which was one of our motivations for conducting this study. Previous work has demonstrated that positive attitudes towards end-of-life care are correlated with specific training. ${ }^{9} 121617$ Nevertheless, three-quarters of nurses in a study in Vietnam had insufficient knowledge of geriatric palliative care. ${ }^{18}$ Associations between self-assessed competence to provide end-of-life care and attitudes towards caring for terminally ill patients, to the best of our knowledge, have not yet been empirically examined. Nurses' perceived competence in this area is important for them to carry out their professional duties with confidence.

We developed the following hypothesis for this study: nursing students' attitudes towards caring for terminally ill patients evolve over the course of the curriculum and are influenced by the number of terminally ill persons encountered, self-perceived nursing skills in palliative care and the subjective impact of instruction. To test this hypothesis, the study aimed to determine attitudes towards caring for terminally ill patients among nursing students, as well as the associations of these attitudes with the number of terminally ill persons encountered and the nursing students' age, year of study, self-perceived nursing skills and subjective impact of instruction.

\section{METHODS}

\section{Study design and setting}

We used the Strengthening the Reporting of Observational Studies in Epidemiology checklist for reporting in cross-sectional studies in writing this article. ${ }^{19}$ This cross-sectional study was conducted from March to May 2019 at the Haute Ecole Arc Sante of the University of Applied Sciences and Arts Western Switzerland. This health sciences school, which enrols about 400 students (140 preparatory students and 260 nursing students) spread over two locations in Switzerland (Neuchâtel and Delémont), offers a 3-year bachelor's degree in nursing science and a related preparatory programme. The preparatory programme is a 1-year course to prepare students who want to enter the nursing curriculum or other health programmes (ie, to become technicians in medical radiology, physiotherapy, osteopathy, occupational therapy, dietetics and nutrition, or midwifery).

\section{Sampling method and sample size calculation}

Preparatory students, first-year nursing students and third-year nursing students were included as participants. There were no exclusion criteria. Potential participants attended a brief oral presentation about the project. We conducted this information session in the classroom at the end of a class session. The students received a printed information sheet and had a 24-hour period to decide whether they wished to participate in the study. The following day, students interested in participating signed a written informed consent form and were enrolled in the study.

Statistical power was calculated to allow analysis by student year of study subgroups and was therefore not based on the overall number of students. With an error level of less than $5 \%$ and a CI of $95 \%$, considering a population of around 100 students per year of study, 79 participants were necessary for each group (calculation performed with the CustomInsight algorithm at https://www.custominsight.com/articles/randomsample-calculator.asp). We therefore chose to include the total school population for the years of interest, without sampling.

\section{Data collection}

Participants completed a self-report computerised questionnaire. Approximately $15 \mathrm{~min}$ was specifically dedicated to completing the assessment before a normal class session. Participants completed the questionnaires using their personal laptops in a classroom on a health sciences school campus. The principal investigator was present to answer questions. Participants did not talk to each other while filling out the questionnaires. Students who did not wish to participate were instructed not to announce this decision publicly and spent this time on their coursework. This procedure was repeated six times over a 3-week period to reach students in the different years of study at the two school sites. 


\section{Instruments}

Attitudes towards terminally ill patients

Attitudes towards terminally ill patients were assessed using a widely recognised research tool, the Frommelt Attitudes Toward Care of the Dying Scale, Form B (FATCOD, Form B) ${ }^{20}$ which is an adapted version of the original FATCOD ${ }^{21}$ specifically developed for use among students in a variety of programmes of study. The original English questionnaire was translated into French by two native French speakers, and two native English speakers then performed a reverse translation, following standard procedures. ${ }^{22}$ The FATCOD, Form B includes 30 items evaluated on a Likert-type scale scored from 1 to 5 , with half of the items negatively worded (and requiring reverse scoring). The total score ranges from 30 to 150 , with higher scores indicating more positive attitudes. The Cronbach's alpha calculated for this scale in our study was 0.78 .

\section{Secondary measures}

Year of study, gender, age and number of terminally ill persons encountered in personal and professional contexts were assessed. To ensure confidentiality, data on age were collected by category ( $\leq 20,21-23,24-26$ and $\geq 27$ years). Exposure to terminally ill persons was assessed as a categorical variable (never, 1 time, 2-5 times, 6-10 times, and 10 and more times) to reduce response burden.

Self-perceived nursing skills in palliative care were assessed using the Self-Perceived Palliative Care Nursing Competence Scale, ${ }^{23}$ which consists of 34 questions answered on an 11-point Likert-type scale. The original version of this scale is in French. The final score is the mean score on all items and ranges from 0 to 10 , with higher scores indicating more confidence in one's own skills. The Cronbach's alpha calculated for this scale in our study was 0.97 .

The subjective impact of the instruction the nursing students had received so far on their ability to care for terminally ill patients was assessed using two questions: one on skills and the other on personal lived experience. These questions were developed specifically for the present study. Before the main study began, the questions were tested with five students who found them comprehensible, relevant and comprehensive to measure the subjective impact of the instruction received. All study participants scored their previous instruction on each of the two questions from 0 (does not prepare me at all) to 10 (prepares me completely).

The expected impact of their instruction at the end of the study programme was also assessed, again both for skills and for personal lived experience. For both questions, the participants provided a score from 0 (will not be prepared at all) to 10 (will be prepared completely).

\section{Patient and public involvement}

There was no time allocated for patient and public involvement, so we were unable to involve patients in the research.

\section{Statistical analyses}

We conducted descriptive analyses, which are presented as means and SD for continuous variables and as frequencies and proportions for categorical variables. Bivariate associations between the different descriptive factors measured and FATCOD, Form B score were assessed using univariate regression models. With the exception of age, ordered categorical variables were considered continuous in the regression models because only linear trends were observed. Age was included in the regression models as a categorical variable. Then, to control for confounding factors, a multivariate linear regression model was estimated, with FATCOD, Form B score as the response variable and all variables considered in the univariate regression models included as explanatory variables. Because this last analysis was intended as a descriptive model rather than a predictive model, variables weakly associated with the FATCOD, Form B were not removed. ${ }^{24}$ Missing values were handled by multiple imputation: instead of being replaced by a single value, missing values are replaced by several values selected at random from a distribution determined using a model (15 imputations for this study). Statistical analyses were performed using R V.3.6.1 (www.r-project.org), and the mice package V.3.5.0 was used for the imputation.

\section{RESULTS}

\section{Population description}

The participant enrolment process is described in figure 1 . A total of 178 participants were included in the

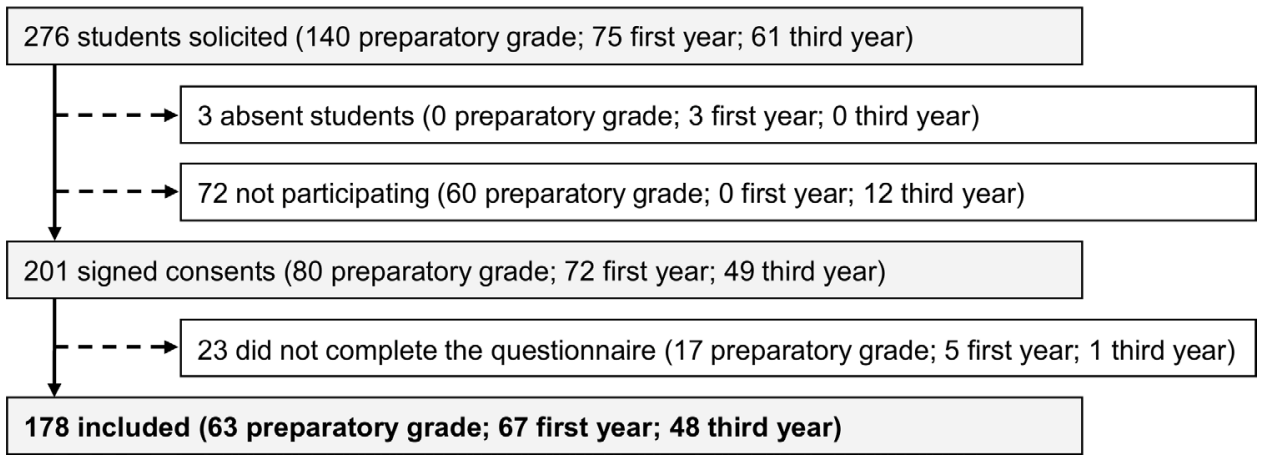

Figure 1 Study flow chart. 
study ( $83.7 \%$ women, median age category: 21-23 years). The overall participation rate was $64 \%$. Of the participants, 63 were in the preparatory programme, and there were 67 first-year and 48 third-year nursing students. The participant characteristics are summarised in table 1.

\section{Attitudes towards caring for terminally ill patients}

The overall mean FATCOD, Form B score was 117.7 (SD: 9.8, median: 118). This shows that nursing students' mean score was three-quarters of the maximum score for positive attitudes towards caring for terminally ill patients. For preparatory students, first-year students and third-year students, the mean scores were 114.9 (SD: 10.1, median: 114), 117.4 (SD: 9.7, median: 116) and 121.9 (SD: 8.2, median: 123.5), respectively.

When we break up the total score to examine each item separately, the most positive attitudes were found for the following items: item 17, 'As a patient nears death, the nonfamily caregiver should withdraw from his/her involvement with the patient' (mean: 4.6, SD: 0.6 , median: 5); item 19, 'The dying person should not allowed to make decisions about his/her physical care' (mean: 4.6, SD: 0.7, median: 5); and item 21, 'It is beneficial for the dying person to verbalize his/her feelings' (mean: 4.6, SD: 0.6, median: 5).

The most negative attitudes were associated with item 3 , 'I would be uncomfortable talking about impending death with the dying person' (mean: 3.1, SD: 1.2, median: $3)$; item 7, 'The length of time required to give care to a dying person would frustrate me' (mean: 2.3, SD: 1.1, median: 2); and item 26, 'I would be uncomfortable if I entered the room of a terminally ill person and found him/her crying' (mean: 3.1, SD: 1.2, median: 3).

\section{Associated factors}

In the bivariate analysis, attitudes towards caring for terminally ill patients were positively associated with nursing student's older age, higher year of study, more frequent professional encounters with terminally ill patients and better self-perceived nursing skills (Self-Perceived Palliative Care Nursing Competence Scale) (table 2).

The multivariate analysis demonstrated that, after controlling for confounding factors, only the positive association with more frequent professionally encountering terminally ill patients remained significant (table 3).

\section{DISCUSSION}

Attitudes towards caring for terminally ill patients are positive and improve as the student's year of study progresses. Professionally encountering terminally ill patients was the strongest factor associated with these attitudes, followed distantly by private experiences with a relative at the end of his or her life. Self-perceived nursing skills in palliative care, year of study and age were other significant factors.
Table 1 Characteristics of the participants, overall and according to the year of study

\begin{tabular}{|c|c|c|c|c|}
\hline & $\begin{array}{l}\text { Total } \\
\text { sample } \\
(n=178)\end{array}$ & $\begin{array}{l}\text { Preparatory } \\
\text { grade } \\
(n=63)\end{array}$ & $\begin{array}{l}\text { First } \\
\text { year } \\
(n=67)\end{array}$ & $\begin{array}{l}\text { Third } \\
\text { year } \\
(n=48)\end{array}$ \\
\hline Women (\%) & 83.7 & 74.6 & 86.6 & 91.7 \\
\hline \multicolumn{5}{|l|}{ Age (\%) } \\
\hline$\leq 20$ years & 35.4 & 66.7 & 31.3 & 0 \\
\hline $21-23$ years & 44.9 & 20.6 & 50.7 & 68.8 \\
\hline 24-26 years & 10.7 & 6.3 & 9.0 & 18.8 \\
\hline$\geq 27$ years & 9.0 & 6.3 & 9.0 & 12.5 \\
\hline \multicolumn{5}{|c|}{ Private encountering (\%) } \\
\hline Never & 10.1 & 15.9 & 7.5 & 6.3 \\
\hline 1 time & 23.6 & 19.0 & 32.8 & 16.7 \\
\hline $2-5$ times & 57.3 & 54.0 & 52.2 & 68.8 \\
\hline $6-10$ times & 7.3 & 7.9 & 7.5 & 6.3 \\
\hline$>10$ times & 1.7 & 3.2 & 0 & 2.1 \\
\hline \multicolumn{5}{|c|}{ Professional encountering (\%) } \\
\hline Never & 14.0 & 25.4 & 13.4 & 0 \\
\hline 1 time & 28.7 & 38.1 & 34.3 & 8.3 \\
\hline $2-5$ times & 43.8 & 30.2 & 43.3 & 62.5 \\
\hline $6-10$ times & 8.4 & 4.8 & 6.0 & 16.7 \\
\hline$>10$ times & 5.1 & 1.6 & 3.0 & 12.5 \\
\hline $\begin{array}{l}\text { SPCNC ( } 33 \\
\text { missing) }\end{array}$ & $4.8(1.9)$ & $4.1(1.7)$ & $4.4(1.6)$ & $6.3(1.5)$ \\
\hline $\begin{array}{l}\text { SPCNC } \\
\text { (imputed) }\end{array}$ & $4.8(1.8)$ & $4.1(1.7)$ & $4.4(1.5)$ & $6.2(1.5)$ \\
\hline $\begin{array}{l}\text { Instruction's } \\
\text { impact-skills }\end{array}$ & $4.3(2.2)$ & $4.0(2.0)$ & $3.4(1.8)$ & $5.8(2.3)$ \\
\hline $\begin{array}{l}\text { Instruction's } \\
\text { impact-lived } \\
\text { experience }\end{array}$ & $4.4(2.5)$ & $4.6(2.4)$ & $3.4(2.2)$ & $5.7(2.3)$ \\
\hline $\begin{array}{l}\text { Expected } \\
\text { impact-skills } \\
\text { ( } 7 \text { missing) }\end{array}$ & $6.3(2.4)$ & $6.6(2.5)$ & $6.3(2.3)$ & $5.9(2.3)$ \\
\hline $\begin{array}{l}\text { Expected } \\
\text { impact-skills } \\
\text { (imputed) }\end{array}$ & $6.2(2.4)$ & $6.4(2.5)$ & $6.3(2.3)$ & $5.9(2.3)$ \\
\hline $\begin{array}{l}\text { Expected } \\
\text { impact-lived } \\
\text { experience (8 } \\
\text { missing) }\end{array}$ & $6.3(2.4)$ & $6.7(2.3)$ & $6.3(2.4)$ & $5.8(2.4)$ \\
\hline $\begin{array}{l}\text { Expected } \\
\text { impact-lived } \\
\text { experience } \\
\text { (imputed) }\end{array}$ & $6.3(2.4)$ & $6.5(2.4)$ & $6.4(2.5)$ & $5.8(2.4)$ \\
\hline
\end{tabular}

Results are expressed as mean (SD) for quantitative variables and as proportions for categorical variables.

SPCNC, self-perceived palliative care nursing competence.;

\section{Attitudes}

The overall attitudes score was three-quarters of the maximum possible score, which shows that nursing 
Table 2 Analysis of bivariate associations between the different descriptive elements and the Frommelt Attitudes Toward Care of the Dying Scale, Form B (FATCOD, Form B)

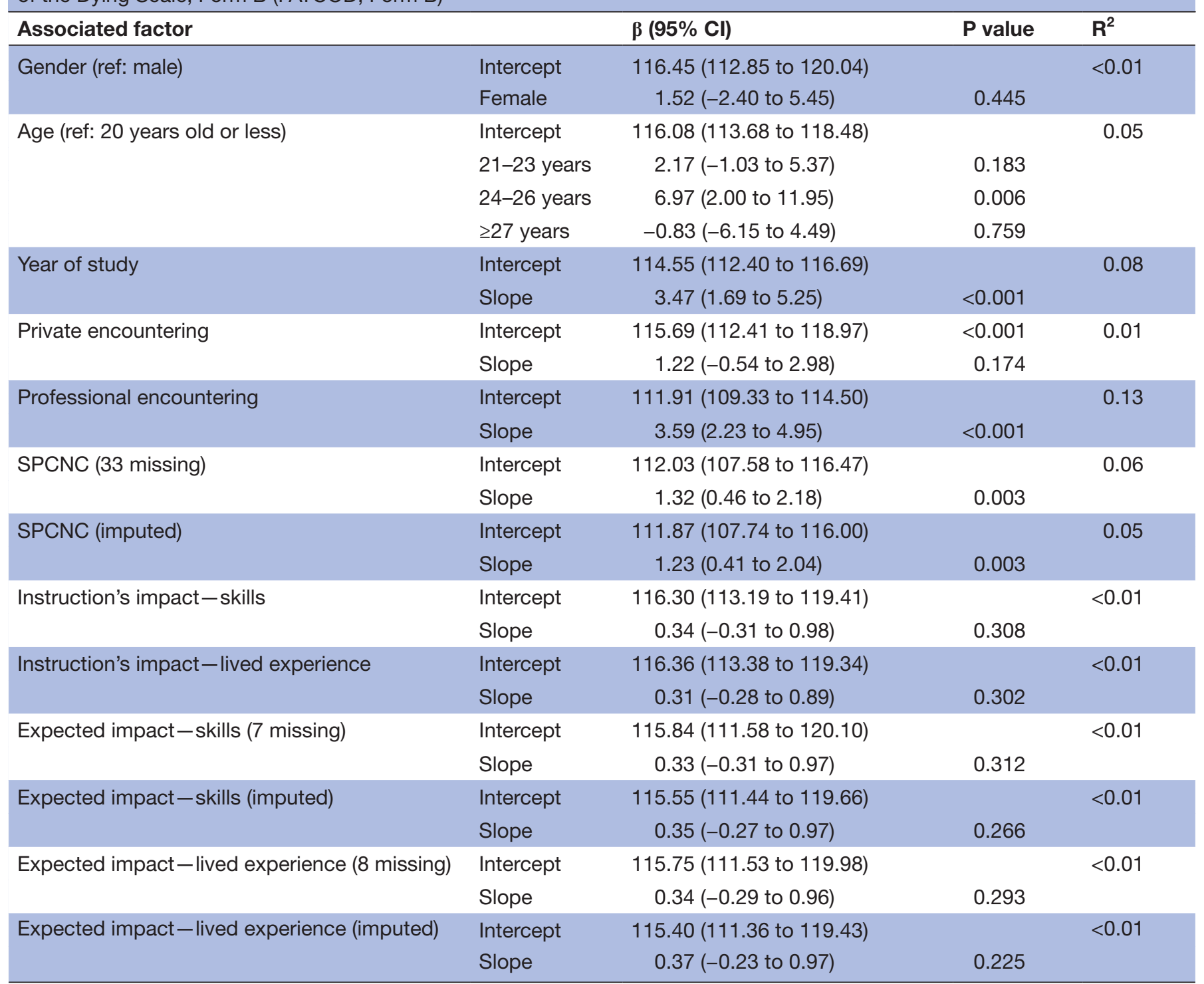

Factors coding: year of study: $0=$ preparatory year, $1=$ first year, $2=$ second year, $3=$ third year; private and professional encountering: $0=$ never, $1=1$ time, $2=2-5$ times, $3=6-10$ times, $4=10$ or more; SPCNC: $0-10$ (higher score indicating higher perception); impact: 0-10 (higher score indicating positive impact).

$\beta$, regression coefficient; $\mathrm{R}^{2}$, coefficient of determination; SPCNC, self-perceived palliative care nursing competence.;

students have very positive attitudes towards caring for terminally ill patients. This positive view may be explained by the students' understanding of caring for vulnerable patients and offering holistic compassionate care as a core value of the nursing profession. Nurses, especially those working in palliative care, consider it an ethical responsibility to support patients and make sure that they understand that they will not be abandoned: Ricot has called this the 'duty of fraternity', which is the 'obligation of a human presence, always attentive, often discreet, sometimes silent'. ${ }^{25}$ This vision is widely recognised, as both patients and professionals have a positive view of professionals taking care of end-of-life patients and attribute qualities such as kindness, warmth, compassion and genuineness to those fulfilling this role. ${ }^{26}$ Finally, students may recognise that the challenge of being professionally confronted with death can lead to personal growth. ${ }^{27}$

The attitudes towards death among participants in our study were more positive than those found among nursing students in Palestine and Turkey, ${ }^{15} 28$ similar to those found among nursing students in the $\mathrm{USA}^{29}$ and poorer than those found among nursing students in Sweden. ${ }^{30}$ Further, our sample of nursing students had more positive attitudes than those found among registered nurses in China, ${ }^{8}$ India, ${ }^{31}{ }^{32}$ Ethiopia, ${ }^{33}$ Saudi Arabia ${ }^{17}$ and Japan ${ }^{9}$; however, nurses in Israel ${ }^{5}$ and the $\mathrm{USA}^{34}$ have been found to have more positive attitudes than those seen in the present study.

Differences between our sample and the samples used in studies conducted in other countries may be explained 
Table 3 Multivariate linear regression of factors associated with the Frommelt Attitudes Toward Care of the Dying Scale, Form B (FATCOD, Form B)

\begin{tabular}{|c|c|c|c|c|c|c|}
\hline \multirow[b]{2}{*}{ Associated factor } & \multicolumn{3}{|l|}{ Without imputation } & \multicolumn{3}{|l|}{ With imputation } \\
\hline & $\beta(95 \% \mathrm{Cl})$ & $P$ value & $\mathbf{R}^{2}$ & $\beta(95 \% \mathrm{Cl})$ & $P$ value & $\mathbf{R}^{2}$ \\
\hline Intercept & 105.06 (95.35 to 114.77$)$ & & 0.20 & 105.94 (97.90 to 113.98$)$ & & 0.21 \\
\hline $21-23$ years & $1.07(-3.35$ to 5.49$)$ & 0.632 & & $-0.11(-3.84$ to 3.62$)$ & 0.953 & \\
\hline $24-26$ years & $4.53(-1.51$ to 10.57$)$ & 0.140 & & $3.99(-1.17$ to 9.14$)$ & 0.129 & \\
\hline Year of study & $1.45(-1.55$ to 4.45$)$ & 0.340 & & $1.97(-0.48$ to 4.42$)$ & 0.115 & \\
\hline Private encountering & $-0.36(-2.43$ to 1.71$)$ & 0.733 & & $0.51(-1.17$ to 2.20$)$ & 0.549 & \\
\hline Professional encountering & 2.81 (0.97 to 4.65$)$ & 0.003 & & $3.00(1.43$ to 4.57$)$ & $<0.001$ & \\
\hline SPCNC & $0.89(-0.26$ to 2.03$)$ & 0.129 & & $0.51(-0.50$ to 1.53$)$ & 0.318 & \\
\hline Expected impact-lived experience & $0.52(-0.89$ to 1.93$)$ & 0.465 & & $0.25(-0.79$ to 1.29$)$ & 0.638 & \\
\hline
\end{tabular}

$\beta$, regression coefficient; $R^{2}$, coefficient of determination.; SPCNC, self-perceived palliative care nursing competence.;

by cultural variations across the studied countries. ${ }^{30}$ This explanation is consistent with the results of research conducted in the USA that showed a significant relationship between students' ethnicity and their attitudes towards the end of life and death. ${ }^{35}$ Religious beliefs inherent to a specific culture could also play a role, as suggested by a Turkish study finding that students who considered themselves non-believers had worse attitudes towards caring for terminally ill patients than did students with religious beliefs. ${ }^{15}$

Another contributing factor could be differences in the health system in place. Previous findings have shown that the integration of palliative care with education for nurses regarding end-of-life situations is the most important factor influencing attitudes towards palliative care. ${ }^{1735}$ National health systems are influenced by the socioeconomic level of the country, which may explain the higher scores found in European countries and the USA, compared with other countries.

\section{Associated factors}

\section{Year of study and age}

Attitudes towards caring for terminally ill patients are positively associated with older age and more advanced year of study. These results are consistent with previous studies demonstrating the effects of age $e^{411123536}$ and training. ${ }^{137}$ Lack of experience may also explain why, in our results, the most positively rated items are those that highlight the patient's well-being and the most negatively rated items are those concerning elements that nurses say they are afraid they will be unable to tolerate.

In addition, as noted above, previous studies conducted in the USA have reported better attitudes among registered nurses than among nursing students. ${ }^{29}{ }^{33}$ This may explain why our sample of young students had poorer attitudes compared with those of registered nurses in some other countries.

\section{Exposure}

The number of end-of-life patients encountered professionally is the most important factor influencing attitudes in this study. Indeed, meeting and providing care to endof-life patients is the key to developing positive attitudes. This finding is consistent with previous studies. ${ }^{71435} 36$ It can be assumed that exposure demystifies the end of life and thereby reduces anxiety. Furthermore, this kind of exposure provides opportunities for the development of knowledge and skills and for personal growth. These changes positively influence attitudes towards future endof-life patients. Correspondently, it has been established that specific palliative care training is correlated with positive attitudes towards end-of-life care. ${ }^{912} 1617$ Conversely, a negative experience can be expected to have a detrimental influence on attitudes, and adequate supervision should therefore be available to help nursing students to overcome this kind of experience.

\section{Skills}

Attitudes towards caring for terminally ill patients are associated with self-perceived nursing skills. Our results are in line with findings previously published by Max and Mackenzie in a poster abstract, where self-perceived nursing skills were assessed with a knowledge assessment. ${ }^{35}$ This finding suggests that caregivers who feel comfortable and competent with end-of-life care have a positive attitude towards providing such care. For nursing students, this means that positive attitudes could be fostered through confidence building, targeted teaching and individually 
rewarding exercises. This idea is supported by previous studies showing that focused end-of-life care simulation exercises $^{32} 3839$ and education ${ }^{40} 41$ improved nursing students' attitudes towards caring for terminally ill patients.

\section{Expected impact}

Third-year nursing students, who are just months from the end of their studies, do not expect further progress. Preparatory students and first-year nursing students are confident that they will improve during the course of their studies, in terms of both skills and lived experience. This is an encouraging result for nursing teachers, as it reflects students' motivation to improve and trust in the school's resources. In addition to courses (including palliative care courses) and internships, the presence of a nursing simulation centre could contribute to these improvements: several studies have shown the strong role of simulation in teaching, which has been described as a highly effective strategy to improve the connection between theory and practice. ${ }^{42-44}$

We could not demonstrate a link between the expected impact of instruction at the end of the students' curriculum and the examined attitudes. This is likely explained by the variability between participants, including their self-confidence. Variability in the participants' exposure to death in their own lives may also have played a role here. Indeed, a previous study has shown that nurses have varied personal experiences with death. ${ }^{45}$

\section{Strengths and limitations}

The primary outcome in this study was assessed with a widely recognised research tool. We used this tool in a geographic setting where nursing students' attitudes towards the management of terminally ill patients had not previously been assessed. Our analyses confirmed that this tool had good internal consistency.

The present study was conducted in one school, with students spread over two sites in Switzerland. This element of the study design must be considered before attempting to generalise the results to other demographic and public health contexts.

Only $80 \%$ (preparatory students), $85 \%$ (first-year students) and $61 \%$ (third-year students) of the calculated sample size was reached, which may have slightly reduced the statistical power. However, we believe that the magnitude of this reduction was minimal. Furthermore, the overall participation rate was satisfactory $(64 \%)$.

The secondary measures used in this study have not all been fully psychometrically validated. In particular, the questions we developed specifically for this study have not been subjected to a full psychometric validation process. Furthermore, data on age and exposure to terminally ill patients were collected as categorical variables, which may have decreased the accuracy of our analyses. Future studies should include age and exposure to terminally ill patients as continuous variables.

\section{Implications for nursing schools}

On the basis of our results, we believe that nursing students should not be removed or protected from situations concerning death during their internships. Early occupational exposure is essential for reducing students' anxiety. Thus, students must be confronted with these situations. To come through these experiences positively, students should be supported and provided with the necessary resources. Both in class and in practical settings, teachers must foster confidence through positive experiences and feedback to enhance students' self-perceived competence. We can also imagine the benefit of classes where students meet with families who have recently lost a loved one. Adopting these approaches should greatly improve the positive attitudes and skills of nursing students and nurses regarding end-of-life care and help them to provide high-quality, holistic care to patients at the end of life.

\section{CONCLUSION}

Nursing students have positive attitudes towards caring for end-of-life patients, and these attitudes improve as the students' year of study progresses. In addition, better attitudes towards terminally ill patients are significantly associated with older age, professional encounters with terminally ill patients and self-perceived palliative care nursing competence. Our study highlights the importance of students experiencing end-of-life care by being in direct contact with end-of-life patients. Future research should develop and assess pedagogic interventions aiming to provide nursing students with appropriate experiences of this type. In addition to contact with patients during internships, we encourage training with simulated patients. This kind of training programme would allow students to gain an increased sense of perceived competence. This is a key point in helping nurses to feel confident in their ability to support patients by being truly present at the time of death.

Acknowledgements We thank Edanz Group (www.edanzediting.com) for editing of a draft of this manuscript.

Contributors PL, TJ, JFD, DT and MAB designed the research. JP and MAB conducted the statistical analysis. All authors interpreted the data. PL and MAB wrote the first draft of the manuscript. All authors participated in the writing of subsequent versions and approved the final article.

Funding This work was supported by the University of Applied Sciences and Arts Western Switzerland (HES-SO, www.hes-so.ch/).

Competing interests None declared.

Patient consent for publication Not required.

Ethics approval In case of suffering caused by participating in the study, the principal investigator was available to listen and provide assistance. The school nurse, who was also informed, was available to provide any necessary follow-up care. The study was performed in agreement with the Helsinki Declaration and its amendments, and in accordance with the applicable Swiss legislation. Since the project did not deal with diseases or the functioning of the human body, it did not fall within the scope of the Human Research Ordinance. This information was formally verified with the Ethics Commission of Canton Vaud (CER-VD, www.cer-vd. $\mathrm{ch}$ ), which indicated that there was no need to submit our protocol for evaluation.

Provenance and peer review Not commissioned; externally peer reviewed. 
Data availability statement Data are available upon reasonable request.

Open access This is an open access article distributed in accordance with the Creative Commons Attribution Non Commercial (CC BY-NC 4.0) license, which permits others to distribute, remix, adapt, build upon this work non-commercially, and license their derivative works on different terms, provided the original work is properly cited, appropriate credit is given, any changes made indicated, and the use is non-commercial. See: http://creativecommons.org/licenses/by-nc/4.0/.

\section{ORCID iDs}

Pauline Laporte http://orcid.org/0000-0001-9557-8021

Jérôme Pasquier http://orcid.org/0000-0002-5554-2988

Marc-Antoine Bornet http://orcid.org/0000-0003-2113-2099

\section{REFERENCES}

1 Giezendanner S, Jung C, Banderet H-R, et al. General practitioners' attitudes towards essential competencies in end-of-life care: a crosssectional survey. PLoS One 2017;12:e0170168.

2 Merlane H, Cauwood L. Core principles of end-of-life care. Br J Nurs 2020;29:280-2.

3 Muñoz-Pino IP. Experience of nursing students upon their first care encounter with terminally ill patients. Invest Educ Enferm 2014;32:87-94.

4 Lange M, Thom B, Kline NE. Assessing nurses' attitudes toward death and caring for dying patients in a comprehensive cancer center. Oncol Nurs Forum 2008;35:955-9.

5 Braun M, Gordon D, Uziely B. Associations between oncology nurses' attitudes toward death and caring for dying patients. Oncol Nurs Forum 2010;37:E43-9.

6 Leclerc B-S, Lessard S, Bechennec C, et al. Attitudes toward death, dying, end-of-life palliative care, and interdisciplinary practice in long term care workers. J Am Med Dir Assoc 2014:15:207-13.

7 Feldman-Desrousseaux E. Prendre soin de l'autre souffrant : la relation soignant-soigné en soins palliatifs. Paris: Seli Arslan, 2007.

8 Wang L, Li C, Zhang Q, et al. Clinical nurses' attitudes towards death and caring for dying patients in China. Int $J$ Palliat Nurs 2018:24:33-9.

9 Matsui M, Braun K. Nurses' and care workers' attitudes toward death and caring for dying older adults in Japan. Int $J$ Palliat Nurs 2010;16:593-8.

10 Gurdogan EP, Kınıcı E, Aksoy B. The relationship between death anxiety and attitudes toward the care of dying patient in nursing students. Psychol Health Med 2019;24:843-52.

11 Dimoula M, Kotronoulas G, Katsaragakis S, et al. Undergraduate nursing students' knowledge about palliative care and attitudes towards end-of-life care: a three-cohort, cross-sectional survey. Nurse Educ Today 2019;74:7-14.

12 Mahiro S, Takashi N, Satoko N. Work engagement and attitudes toward caring for dying patients and families among home-visiting nurses in Japan. Int J Palliat Nurs 2014;20:343-8.

13 Paul SS, Renu G, Thampi PT. Creating a positive attitude toward dying patients among nursing students: is the current curriculum adequate? Indian J Palliat Care 2019;25:142-6.

14 Iranmanesh S, Savenstedt S, Abbaszadeh A. Student nurses' attitudes towards death and dying in south-east Iran. Int $J$ Palliat Nurs 2008:14:214-9.

15 Arslan D, Akca NK, Simsek N, et al. Student nurses' attitudes toward dying patients in central Anatolia. Int J Nurs Knowl 2014;25:183-8.

16 Sakai M, Naruse T, Nagata S. Home visiting nurses' attitudes toward caring for dying patients, and related workplace factors. Int J Palliat Nurs 2013;19:195-204.

17 Abudari G, Zahreddine $\mathrm{H}$, Hazeim $\mathrm{H}$, et al. Knowledge of and attitudes towards palliative care among multinational nurses in Saudi Arabia. Int J Palliat Nurs 2014;20:435-41.

18 Vu HTT, Nguyen LH, Nguyen TX, Hoang Nguyen L, et al. Knowledge and attitude toward geriatric palliative care among health professionals in Vietnam. Int J Environ Res Public Health 2019;16:10.3390/ijerph16152656.

19 von Elm E, Altman DG, Egger M, et al. The strengthening the reporting of observational studies in epidemiology (STROBE) statement: guidelines for reporting observational studies. Int J Surg 2014:12:1495-9.

20 Frommelt KHM. Attitudes toward care of the terminally ill: an educational intervention. Am J Hosp Palliat Care 2003;20:13-22.

21 Frommelt $\mathrm{KH}$. The effects of death education on nurses' attitudes toward caring for terminally ill persons and their families. Am J Hosp Palliat Care 1991;8:37-43.

22 Sousa VD, Rojjanasrirat W. Translation, adaptation and validation of instruments or scales for use in cross-cultural health care research: a clear and user-friendly guideline. J Eval Clin Pract 2011;17:268-74.

23 Desbiens JF. Développement et validation d'une mesure de perception de compétence infirmière en soins palliatifs. Laval University, 2011.

24 Sauerbrei W, Perperoglou A, Schmid M, et al. State of the art in selection of variables and functional forms in multivariable analysisoutstanding issues. Diagn Progn Res 2020;4:3

25 Ricot J. Histoire et éthique des soins palliatifs. In: Cités. , 2016: 66, 49-58.

26 Johnston B, Smith LN. Nurses' and patients' perceptions of expert palliative nursing care. J Adv Nurs 2006;54:700-9.

27 Barnard A, Hollingum C, Hartfiel B. Going on a journey: understanding palliative care nursing. Int J Palliat Nurs 2006;12:6-12.

28 Abu-El-Noor NI, Abu-El-Noor MK. Attitude of palestinian nursing students toward caring for dying patients. $J$ Holist Nurs 2016;34:193-9.

29 Mallory JL. The impact of a palliative care educational component on attitudes toward care of the dying in undergraduate nursing students. J Prof Nurs 2003;19:305-12.

30 Henoch I, Browall M, Melin-Johansson C, et al. The Swedish version of the Frommelt attitude toward care of the dying scale: aspects of validity and factors influencing nurses' and nursing students' attitudes. Cancer Nurs 2014;37:E1-11.

31 Lancaster RJ, Kautzmann C, Micheal JCJ, et al. Attitudes of nurses towards care of the dying patient in India. Int $J$ Palliat Nurs 2017;23:558-66.

32 Jafari M, Rafiei H, Nassehi A, et al. Caring for dying patients: attitude of nursing students and effects of education. Indian J Palliat Care 2015;21:192-7.

33 Kassa H, Murugan R, Zewdu F, et al. Assessment of knowledge, attitude and practice and associated factors towards palliative care among nurses working in selected hospitals, Addis Ababa, Ethiopia. BMC Palliat Care 2014:13:6.

34 Dunn KS, Otten C, Stephens E. Nursing experience and the care of dying patients. Oncol Nurs Forum 2005;32:97-104.

35 Max E, Mackenzie MA. Just in KASE. Evaluating Nursing Students Knowledge, Attitudes, and Self-Efficacy Toward Care for the Dying Patients. J Hosp Palliat Nurs 2017;19:356-62.

36 Hagelin CL, Melin-Johansson C, Henoch I, et al. Factors influencing attitude toward care of dying patients in first-year nursing students. Int J Palliat Nurs 2016;22:28-36.

37 A'la MZ, Setioputro B, Kurniawan DE. Nursing Students' Attitudes towards Caring for Dying Patients. Nurse Media Journal of Nursing 2018;8:25.

38 Gilliland I. Effects of a community-based hospice experience on attitudes and self-perceived competencies of baccalaureate senior nursing students. J Nurs Educ 2015;54:335-8.

39 Carman MJ, Sloane R, Molloy M, et al. Implementation of a learning bundle to promote end-of-life education for Prelicensure nursing students. J Hosp Palliat Nurs 2016;18:356-63.

40 Dobbins EH. The impact of end-of-life curriculum content on the attitudes of associate degree nursing students toward death and care of the dying. Teach Learn Nurs 2011;6:159-66.

41 Bloomfield JG, O'Neill B, Gillett K. Enhancing student communication during end-of-life care: a pilot study. Palliat Support Care 2015;13:1651-61.

42 Gillan PC, Jeong S, van der Riet PJ. End of life care simulation: a review of the literature. Nurse Educ Today 2014;34:766-74.

43 Gillan PC, Parmenter G, van der Riet PJ, et al. The experience of end of life care simulation at a rural Australian university. Nurse Educ Today 2013;33:1435-9.

44 Norman J. Systematic review of the literature on simulation in nursing education. Abnf J 2012;23:24-8.

45 Peters L, Cant R, Payne S, et al. How death anxiety impacts nurses' caring for patients at the end of life: a review of literature. Open Nurs J 2013;7:14-21. 